\title{
YEARS OF SERVICE, SELF-EFFICACY, STRESS AND BURNOUT AMONG POLISH FIREFIGHTERS
}

\author{
MARTA MAKARA-STUDZIŃSKA ${ }^{1}$, ZBIGNIEW WAJDA ${ }^{1}$, and SEBASTIAN LIZIŃCZYK² \\ ${ }^{1}$ Jagiellonian University, Kraków, Poland \\ Medical College, Department of Health Psychology \\ ${ }^{2}$ SWPS University of Social Sciences and Humanities, Katowice, Poland \\ Faculty of Psychology
}

\begin{abstract}
Objectives: The aim of the research was to analyze the impact of selected factors: years of service, the number of interventions, self-efficacy and stress, on occupational burnout. It was hypothesized that firefighters with more years of service and a bigger number of interventions would be characterized by higher perceived stress and burnout, and that self-efficacy would have an impact on reducing the level of perceived stress and burnout. Material and Methods: The participants were firefighters ( $\mathrm{N}=576$ ) from 12 Polish voivodeships, aged 20-58 years, with different seniority: up to 3, 4-8, 9-15 or $>15$ years of service. The following research tools were used: the Link Burnout Questionnaire, the 10-item Perceived Stress Scale, the Generalized Self-Efficacy Scale, and an independent questionnaire to gather additional information. A correlation between particular variables was carried out; the Kruskal-Wallis test was performed together with a post-hoc analysis to examine differences in the severity of individual variables depending on seniority, followed by a path analysis studied together with the identification of direct and indirect impacts. Results: The number of interventions did not affect the severity of experienced stress or any of the aspects of burnout. Work experience directly influenced the level of perceived stress $(\beta=0.219)$, disillusion $(\beta=0.076)$, and relationship deterioration $(\beta=-0.156)$. The generalized sense of self-efficacy was found to impact both on reducing the sense of stress $(\beta=-0.418)$ and on all 4 aspects of professional burnout: psychophysical exhaustion $(\beta=-0.181)$, relationship deterioration $(\beta=-0.16)$, the sense of professional inefficacy $(\beta=-0.275)$ and disillusion $(\beta=-0.143)$. Conclusions: The results have shown that: 1$)$ the number of interventions does not affect the severity of experienced stress or particular aspects of burnout;2) years of service increase the severity of experienced stress and occupational burnout; 3 ) self-efficacy has an impact both on reducing the sense of stress and on all aspects of burnout. Int J Occup Med Environ Health. 2020;33(3):283-97
\end{abstract}

Key words:

stress, burnout, firefighters, self-efficacy, years of service, Link Burnout Questionnaire

\section{INTRODUCTION}

Firefighters are a professional group particularly exposed to stressful situations. Previous studies have shown that this professional group may be exposed to both chronic stress and traumatic events. The sources of chronic stress in the profession of a firefighter include low control over situations at work, a low salary, the fear of losing one's job, insufficient resources, working shifts, and the requirement to be on duty. In turn, traumatic stress includes events directly related to interventions: a direct threat to one's life and to the life and health of one's colleagues, as well as being a witness to the tragedy of other people - including their death [1,2].

Empirical studies have indicated that occupational stress can be a factor which increases the risk of burnout in various groups, e.g., among nurses [3], teachers [4], doctors [5,6],

Funding: this research was supported by the Jagiellonian University Medical College (project No. K/ZDS/007106, entitled "Stress at work, self-efficacy and burnout syndromes - analysis of dependencies in social service professions," project manager: Prof. Marta Makara-Studzińska).

Received: May 13, 2019. Accepted: January 22, 2020.

Corresponding author: Zbigniew Wajda, Neurosis and Eating Disorder Treatment Centre "Dąbrówka”, Asnyka 10, 44-122 Gliwice, Poland (e-mail: zbigniew.wajda@ gmail.com). 
factory employees [7], or the prison service [8]. With respect to the firefighting profession, it can be seen that although studies on this population have an increasing presence in literature, the number of studies is still relatively poorly compared to other professions. Mitani et al. [9] conducted research on a group of firefighters who showed a relationship between burnout and both traumatic and chronic stress. It was shown that social support and interpersonal relations in the workplace mitigated occupational burnout. Similar studies, but on a much larger number of participants, were conducted by Katsavouni et al. [10]. They identified multidimensional relationships between injuries sustained in the course of professional activities, post-traumatic stress disorder (PTSD), burnout syndrome, age and seniority of the participants. Research by Smith et al. [11] showed that occupational stress among firefighters and family-work conflicts were predictors of occupational burnout, which in turn was associated with a decrease in behavior conducive to work safety.

It seems that, apart from the phenomenon of the experience of stress, one of the variables that may have an impact on occupational burnout is also the number of years of stressful work (seniority) to which firefighters are subjected. On the one hand, it can be assumed that young employees who start their professional careers with beliefs that are relatively less realistic may be the most exposed to occupational burnout, as their ideals are often verified by everyday reality. It is also worth noting that novice firefighters (and thus the youngest) go through a period of initial adaptation, verification of their own suitability for the profession, the sense of a low professional position, and the need to develop appropriate mechanisms for coping with stress in their profession. Some studies have confirmed that the highest risk of occupational burnout occurs at the beginning of a firefighter's career and decreases with age and seniority [7,12]. This conclusion, however, is not so obvious, because there are many contradictory reports in this regard. There are studies that point to a positive correlation between age, work experience and burnout [13], the lack of such a correlation [14], as well as a curvilinear (U-shaped) correlation [15].

Cherniss [16] pointed out that a useful psychological variable for understanding the sense of stress and the severity of occupational burnout could be generalized self-efficacy. This concept was introduced to psychology as part of Bandura's theory of social learning [17], and it refers to convictions regarding the possibility of reaching goals or coping with various situations in life. Research on this variable allows one to assume that self-efficacy is also relevant to firefighters in terms of its motivational properties [18], influence on undertaking various activities and coping with stress $[1,19,20]$.

Research has been carried out in Poland on the psychological aspects of firefighters' work, such as the sense of coherence and PTSD [21], stress in the context of firefighters' health [22], experienced stress in the context of other professions [23], the occurrence of post-traumatic reactions, including PTSD and post-traumatic growth (PTG), compared to both firefighters from other countries [24] and other professions [25-29]. This research focuses less often on occupational burnout among Polish firefighters. In one such study, Ogińska-Bulik and Kaflik-Pieróg [1] examined the relationship between stress, the sense of efficacy and burnout. The results they obtained indicate that Polish firefighters present a lower level of burnout compared to policemen, nurses, doctors and teachers. Furthermore, it was shown that although the sense of selfefficacy negatively correlated with exhaustion, it did not significantly correlate with other aspects of occupational burnout.

Basińska and Wiciak [30] studied fatigue and burnout in firefighters and policemen in the context of shift work. This study shows that fatigue increases such components of occupational burnout as psychophysical exhaustion and the lack of commitment to customer relationships. Factors pertaining to the organization of working hours and 
shift work affected fatigue and burnout. Firefighters felt less tired than policemen and nurses, which the authors explained in terms of their work characteristics.

Krok [31] examined the relationships between the meaning in life and burnout among firefighters. Those who had higher levels of personal meaning and the presence of meaning less frequently reported emotional exhaustion and depersonalization, and more frequently efficacy. Most of the personal meaning dimensions (e.g., personal meaning, the presence of meaning, a search for meaning) had significant associations with burnout indicators: the participants with a detached style had higher levels of emotional exhaustion and depersonalization than those with a presence style or with a presence and search style. The above data suggest the lack of a clear answer to the questions pertaining to links between seniority and burnout, especially as previous research was conducted mainly among medical services and teachers, and less frequently among firefighters. As the studies cited above have revealed, the intensity of stress, burnout and working conditions in services differ, and it is, therefore, not possible to translate these data directly from one professional group to another.

It seems that the specific aspects of firefighters' work can have a significant impact on the variables discussed. Firefighters have a characteristic profile of vulnerability to professional stress, which includes direct risks to their own health or life. As revealed by Koniarek and Dudek [25], and Ogińska-Bulik and Kaflik-Pieróg [32], >80\% of firefighters have experienced a traumatic event and $>70 \%$ of them have participated in such an event at least twice. Other data show that each year in the USA about 100 firefighters are killed in action, and that 58835 were injured in 2017 (a decrease of 5\% in comparison to the previous year) $[33,34]$.

Some authors assume that the work of a firefighter is not stressful in itself, but that it becomes stressful when the number of interventions, especially extremely difficult ones, increases [23,33]. Furthermore, the results of research on firefighters in one country do not correspond directly with the results in another country in all instances [24]. Literature reviews show that investigations into professional burnout relatively seldom involved only firefighters, especially when compared to other professions. The scope of each of these studies frequently included traumatic stress (not daily pressures), and the combination of variables was limited to only a few internal (psychological) or external ones, while sample sizes were usually small [21-23,25-30]. To the best of the authors' knowledge, the significance of combinations of individual psychological features (the level of perceived stress, selfefficacy) and factors related to the work itself (the number of years of service, the number of interventions) have not been studied among Polish firefighters.

These premises became the basis for designing a study investigating a large number of firefighters and creating a hypothetical model of mutual links between their experiences relating to this work - the number of interventions, generalized self-efficacy, and perceived stress and individual levels of occupational burnout (Figure 1). It is hypothesized that the number of years of service, the number of interventions in a given year, and the level of perceived stress will have an impact on the increase in professional burnout. In other words, firefighters with higher seniority and who have participated in more interventions will, on the one hand, be characterized by a higher level of experienced stress and show a higher level of occupational burnout. On the other hand, the self-efficacy of firefighters will have an inversely proportional effect both on their levels of experienced stress and particular aspects of burnout.

\section{MATERIAL AND METHODS}

\section{Participants}

The participants were 576 professionally active firefighters from 12 voivodeships in Poland. All subjects were male and 


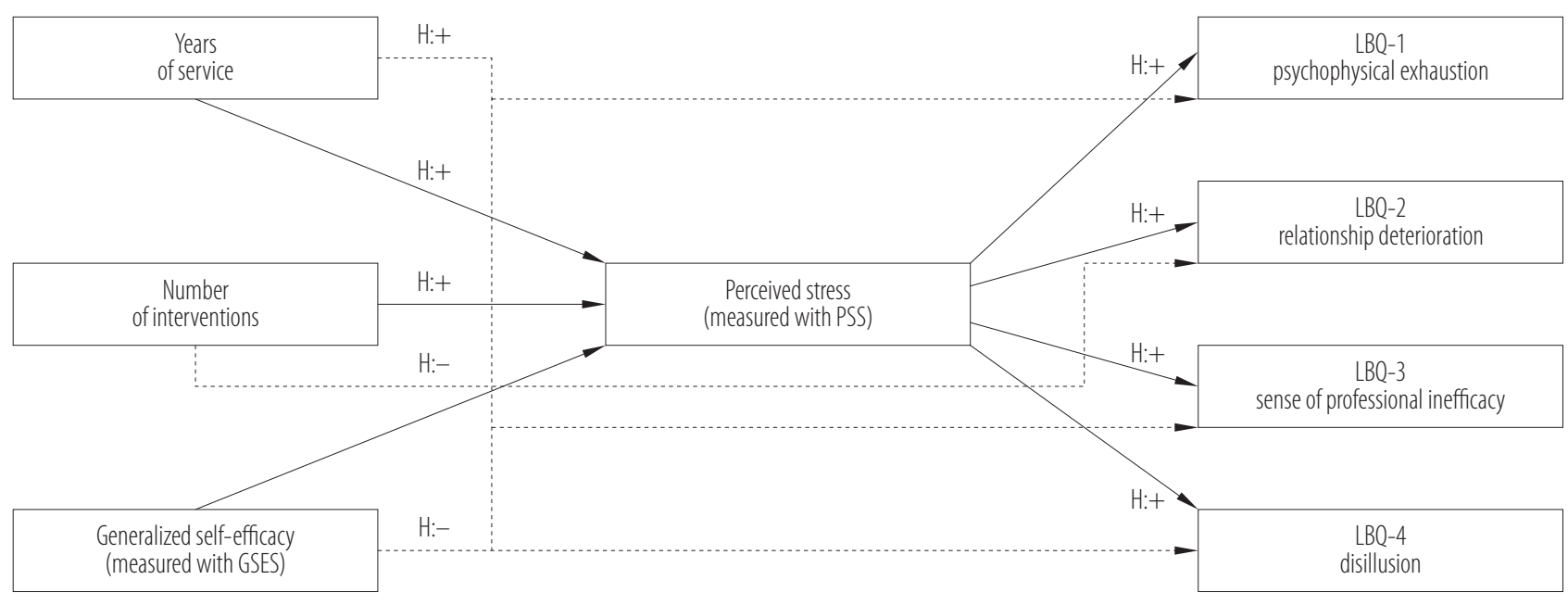

GSES - General Self-Efficacy Scale; LBQ - Link Burnout Questionnaire; PSS - Perceived Stress Scale.

Figure 1. A proposed model of mutual links between experiences relating to firefighters' work in the study on occupational burnout among Polish firefighters

the mean age was 35 years $(\mathrm{SD}=6.72$, $\min .=20$, $\max =$ 58). Among them, there were 42 (7.29\%) rank-and-file firefighters, 315 (54.69\%) with the rank of non-commissioned officer, $131(22.74 \%)$ with the degree of inspector, $61(10.59 \%)$ with the rank of junior officer, and 27 (4.69\%) with the rank of senior officer. As regards the marital status, $112(19.44 \%)$ of the firefighters were unmarried, 427 $(74.13 \%)$ were married, $15(2.60 \%)$ cohabited with a partner, and $22(3.82 \%)$ were separated or divorced. As regards education, $281(48.78 \%)$ of the firefighters had secondary education, $55(9.55 \%)$ post-secondary education, $125(21.70 \%)$ the bachelor's degree, and 115 (19.97\%) the master's degree. The duration of service of the firefighters was: 0-3 years -45 participants $(7.81 \%)$; $4-8$ years - 152 participants (26.39\%); 9-15 years - 238 participants $(41.32 \%)$ and $\geq 16$ years -141 participants $(24.48 \%)$, including 11 participants $(1.91 \%)$ with $>25$ years of service. The firefighters had 972.82 interventions in the previous year on average $(\mathrm{SD}=562.27, \mathrm{Me}=926, \min .=0, \max =$ 2.400). Table 1 below presents selected demographic data for the 4 specific subgroups of firefighters that were created on the basis of their years of service.
These subgroups were set arbitrarily at the research planning stage, and their members completed a specially designed questionnaire in which they were assigned to one of the following subgroups: a short duration of service (0-3 years), a medium duration of service (4-8 years), a long duration of service (9-15 years), and a very long duration of service ( $>15$ years). It was assumed that the number of participants in the individual subgroups would be equal; however, due to the fact that not all of the participants completed the questionnaire, these subgroups had varying numbers.

Table 1 shows that rank in the corps increases with the number of years of service. Family characteristics also change according to the duration of service: workers with fewer years of service are more often unmarried without children, while those who have more years of service are more likely to be married and have children.

\section{Burnout}

The Polish version of the Link Burnout Questionnaire (LBQ) $[35,36]$, created by the Laboratory of Psychological Tests of the Polish Psychological Society [37], 
Table 1. Selected demographic data according to years of service in a group of active firefighters from 12 Polish voivodeships

\begin{tabular}{|c|c|c|c|c|}
\hline \multirow{2}{*}{ Variable } & \multicolumn{4}{|c|}{$\begin{array}{c}\text { Participants } \\
(\mathrm{N}=576)\end{array}$} \\
\hline & $\begin{array}{l}\text { subgroup A } \\
(\mathrm{N}=45)\end{array}$ & $\begin{array}{c}\text { subgroup B } \\
(\mathrm{N}=152)\end{array}$ & $\begin{array}{c}\text { subgroup C } \\
(\mathrm{N}=238)\end{array}$ & $\begin{array}{c}\text { subgroup D } \\
(\mathrm{N}=141)\end{array}$ \\
\hline \multicolumn{5}{|l|}{ Corps $[\%]$} \\
\hline rank-and-file & 64 & 6 & 2 & 0 \\
\hline non-commissioned officer & 9 & 63 & 68 & 37 \\
\hline inspector & 24 & 25 & 18 & 28 \\
\hline officer & 2 & 6 & 12 & 35 \\
\hline \multicolumn{5}{|l|}{ Marital status [\%] } \\
\hline unmarried & 27 & 21 & 22 & 11 \\
\hline married & 67 & 73 & 71 & 84 \\
\hline cohabiting & 2 & 3 & 3 & 2 \\
\hline separated/divorced & 4 & 4 & 4 & 3 \\
\hline widowed & 0 & 0 & 0 & 0 \\
\hline \multicolumn{5}{|l|}{ Children [n] } \\
\hline 0 & 91 & 53 & 15 & 6 \\
\hline 1 & 9 & 21 & 31 & 21 \\
\hline 2 & & 22 & 44 & 61 \\
\hline 3 & & 4 & 7 & 11 \\
\hline 4 & & & 2 & 1 \\
\hline
\end{tabular}

Subgroup A: 0-3 years of service; subgroup B: 4-8 years of service; subgroup C: 9-15 years of service; subgroup D: >15 years of service.

was used. This measure consists of 24 items, in relation to which the subject responds on a 6-point Likert scale (from "never" to "daily"). The questionnaire has 4 dimensions (scales) that are designed to study occupational burnout, i.e., psychophysical exhaustion (LBQ-1), relationship deterioration (LBQ-2), the sense of professional inefficacy (LBQ-3) and disillusion (LBQ-4). Each scale measures these dimensions on a continuum between low and high severity. The questionnaire in the Polish version has good psychometric properties. The scale of disillusion (Cronbach's $\alpha$ 0.84) has the highest internal reliability and the scale pertaining to the sense of professional inefficacy (Cronbach's $\alpha$ 0.68) has the lowest internal reliability. In this research, Cronbach's $\alpha$ for individual scales amounted to 0.82 for psychophysical exhaustion (LBQ-1), 0.73 for relationship deterioration (LBQ-2), 0.60 for the sense of professional inefficacy (LBQ-3), and 0.81 for disillusion (LBQ-4).

\section{Level of stress}

The Polish version of the Perceived Stress Scale (PSS-10) [38] (Juczyński and Ogińska-Bulik [39]) was employed. It contains 10 questions that concern subjective feelings related to personal problems and events, behaviors and ways of coping. The respondent answers the questions using a 5-point Likert scale (from "never" to "very often"). In the Polish version, the scale has obtained very good psychometric properties with a Cronbach's $\alpha$ 
value of 0.86 . In the presented studies, Cronbach's $\alpha$ was 0.82 .

\section{Self-efficacy}

The Polish version of the Generalized Self-Efficacy Scale (GSES) [40,41], based on Bandura's theory of social learning [17], was employed. It consists of 10 questions to which the participant responds using a 4-point Likert scale (from "definitely not" to "definitely yes"). Cronbach's $\alpha$ in the Polish version was 0.85 . In the studies presented in this paper, Cronbach's $\alpha$ was 0.76 .

\section{Demographic and other factors}

The participants were also asked about their age, seniority, corps, education, and other demographic data and characteristics. The duration of service was determined arbitrarily so that it could reflect employees with a short, medium, long, and very long duration of service. The participants completed the questionnaire by choosing the appropriate subgroup.

\section{Ethics}

This project was approved by the Bioethics Committee and was carried out in accordance with the recommendations of the American Psychological Association's Code of Ethics.

\section{Statistics}

The authors used SPSS (version 25) for statistical analyses. The threshold of statistical significance was set at the level of 0.5 . At the preliminary stage, Pearson's $r$ was carried out between all the variables. Then, the obtained mean results and differences between individual variables were presented according to years of service. The KruskalWallis test was used, followed by post-hoc analyses, which revealed differences in the level of the variables for particular subgroups. At the last stage, which used the path analysis in the AMOS program, the relationship between the number of years of service, generalized self-efficacy, perceived stress and various aspects of burnout were presented.

Previous studies [11] have indicated the possibility of significant correlations between family factors and stress at work, and, as the results of the path analyses obtained by the authors also indicated that possibility, it was decided to perform several additional analyses that were not included in the initial research plan. The level of perceived stress and 4 aspects of occupational burnout in the married and unmarried participants were compared using Student's t-test.

\section{RESULTS}

Table 2 shows the correlation between the number of years of service, the average number of interventions in 2016, the level of experienced stress, the sense of generalized self-efficacy, and individual aspects of burnout: psychophysical exhaustion, relationship deterioration, the sense of professional inefficacy, and disillusion. The results indicate that the number of years of service as a firefighter significantly correlates with all of the dimensions of professional burnout, as well as with the level of perceived stress. These correlations, though weak, are significant. The number of interventions in the year preceding the survey did not reveal any significant relationships. It is probably not the number of interventions or their particular circumstances that may play an important role in the burnout process. The results show that the variable "generalized self-efficacy" is an important factor that negatively correlates with the dimensions of professional burnout as well as with the level of experienced stress. In contrast, the level of experienced stress was significantly and positively related to the dimensions of occupational burnout. The statistical analyses further showed that the seniority of the firefighters predicted the value of the variables.

Table 3 shows the means and standard deviations for all of the variables tested for each of the subgroups, pertain- 
Table 2. Pearson's correlations between the variables in a group of active firefighters $(\mathrm{N}=576)$ from 12 Polish voivodeships

\begin{tabular}{lcccc}
\hline \multicolumn{1}{c}{ Variable } & \multicolumn{3}{c}{ Pearson's correlations } \\
\cline { 2 - 4 } & 1. & 2. & 3. & 4. \\
\hline Work-related variables & & & \\
$\quad$ 1. Years of service & - & & \\
2. Average number of interventions in 2016 & $0.091^{*}$ & - & \\
General Self-Efficacy Scale & & & \\
3. Generalized self-efficacy & -0.016 & 0.06 & - & \\
Perceived Stress Scale & & & & - \\
4. Perceived stress & $0.226^{* * *}$ & -0.035 & $-0.420^{* * *}$ & \\
Link Burnout Questionnaire & & & & \\
5. Psychophysical exhaustion (LBQ-1) & $0.137^{* * *}$ & -0.34 & $-0.353^{* * *}$ & $0.494^{* * *}$ \\
6. Relationship deterioration (LBQ-2) & $-0.092^{*}$ & -0.61 & $-0.273^{* * *}$ & $0.300^{* * *}$ \\
7. Sense of professional inefficacy (LBQ-3) & $0.092^{*}$ & -0.014 & $-0.377^{* * *}$ & $0.363^{* * *}$ \\
8. Disillusion (LBQ-4) & $0.164^{* * *}$ & -0.049 & $-0.304^{* * *}$ & $0.457^{* * * *}$ \\
\hline
\end{tabular}

$* * *$ Statistical significance $<0.001 ; * *$ statistical significance $<0.01 ; *$ statistical significance $<0.05$.

Table 3. Differences in the severity of experienced stress and particular aspects of occupational burnout, depending on the number of years of service, using the Kruskal-Wallis test followed by the Dunn-Bonferroni post-hoc test, in a group of active firefighters from 12 Polish voivodeships

\begin{tabular}{|c|c|c|c|c|c|}
\hline \multirow[t]{2}{*}{ Variable } & \multicolumn{4}{|c|}{$\begin{array}{c}\text { Participants } \\
(\mathrm{N}=576) \\
(\mathrm{M} \pm \mathrm{SD})\end{array}$} & \multirow[t]{2}{*}{$\mathrm{p}$} \\
\hline & $\begin{array}{l}\text { subgroup A } \\
(\mathrm{N}=45)\end{array}$ & $\begin{array}{l}\text { subgroup B } \\
(\mathrm{N}=152)\end{array}$ & $\begin{array}{c}\text { subgroup C } \\
(\mathrm{N}=238)\end{array}$ & $\begin{array}{c}\text { subgroup D } \\
(\mathrm{N}=141)\end{array}$ & \\
\hline \multicolumn{6}{|l|}{ Perceived Stress Scale } \\
\hline perceived stress ${ }^{\mathrm{a}}$ & $11.84 \pm 5.64$ & $13.64 \pm 5.60$ & $15.44 \pm 5.29$ & $16.14 \pm 6.03$ & 0.001 \\
\hline post-hoc $c^{\mathrm{b}}$ & \multicolumn{5}{|c|}{$\mathrm{A}<\mathrm{C}: \mathrm{p}<0.001 ; \mathrm{A}<\mathrm{D}: \mathrm{p}<0.001 ; \mathrm{B}<\mathrm{C}: \mathrm{p}<0.01 ; \mathrm{B}<\mathrm{D}: \mathrm{p}<0.001$} \\
\hline \multicolumn{6}{|l|}{ Link Burnout Questionnaire } \\
\hline psychophysical exhaustion (LBQ-1) ${ }^{\mathrm{a}}$ & $12.93 \pm 4.71$ & $15.24 \pm 4.93$ & $16.12 \pm 5.74$ & $16.40 \pm 6.13$ & 0.01 \\
\hline post-hoc $c^{\mathrm{b}}$ & \multicolumn{4}{|c|}{$\mathrm{A}<\mathrm{C}: \mathrm{p}<0.01 ; \mathrm{A}<\mathrm{D}: \mathrm{p}<0.01$} & \\
\hline relationship deterioration (LBQ-2) ${ }^{\mathrm{a}}$ & $16.48 \pm 3.73$ & $16.85 \pm 3.89$ & $16.92 \pm 4.55$ & $15.54 \pm 4.7$ & 0.001 \\
\hline post-hoc $c^{\mathrm{b}}$ & \multicolumn{4}{|c|}{$\mathrm{C}>\mathrm{D}: \mathrm{p}<0.05$} & \\
\hline sense of professional inefficacy $(\mathrm{LBQ}-3)^{\mathrm{a}}$ & $12.02 \pm 4.14$ & $13.08 \pm 3.97$ & $13.79 \pm 4.51$ & $13.77 \pm 4.65$ & 0.05 \\
\hline post-hoc & \multicolumn{4}{|c|}{$\mathrm{A}<\mathrm{C}: \mathrm{p}<0.05$} & \\
\hline disillusion (LBQ-4) ${ }^{\mathrm{a}}$ & $9.97 \pm 4.19$ & $12.73 \pm 5.45$ & $14.72 \pm 6.28$ & $14.19 \pm 6.56$ & 0.001 \\
\hline post-hoc & \multicolumn{4}{|c|}{$\mathrm{A}<\mathrm{B}: \mathrm{p}<0.05 ; \mathrm{A}<\mathrm{C}: \mathrm{p}<0.001 ; \mathrm{A}<\mathrm{D}: \mathrm{p}<0.001 ; \mathrm{B}<\mathrm{C}: \mathrm{p}<0.05$} & \\
\hline
\end{tabular}

${ }^{\mathrm{a}}$ Kruskal-Wallis test; ${ }^{\mathrm{b}}$ Dunn-Bonferroni post-hoc test.

Explanations as in Table 1. 


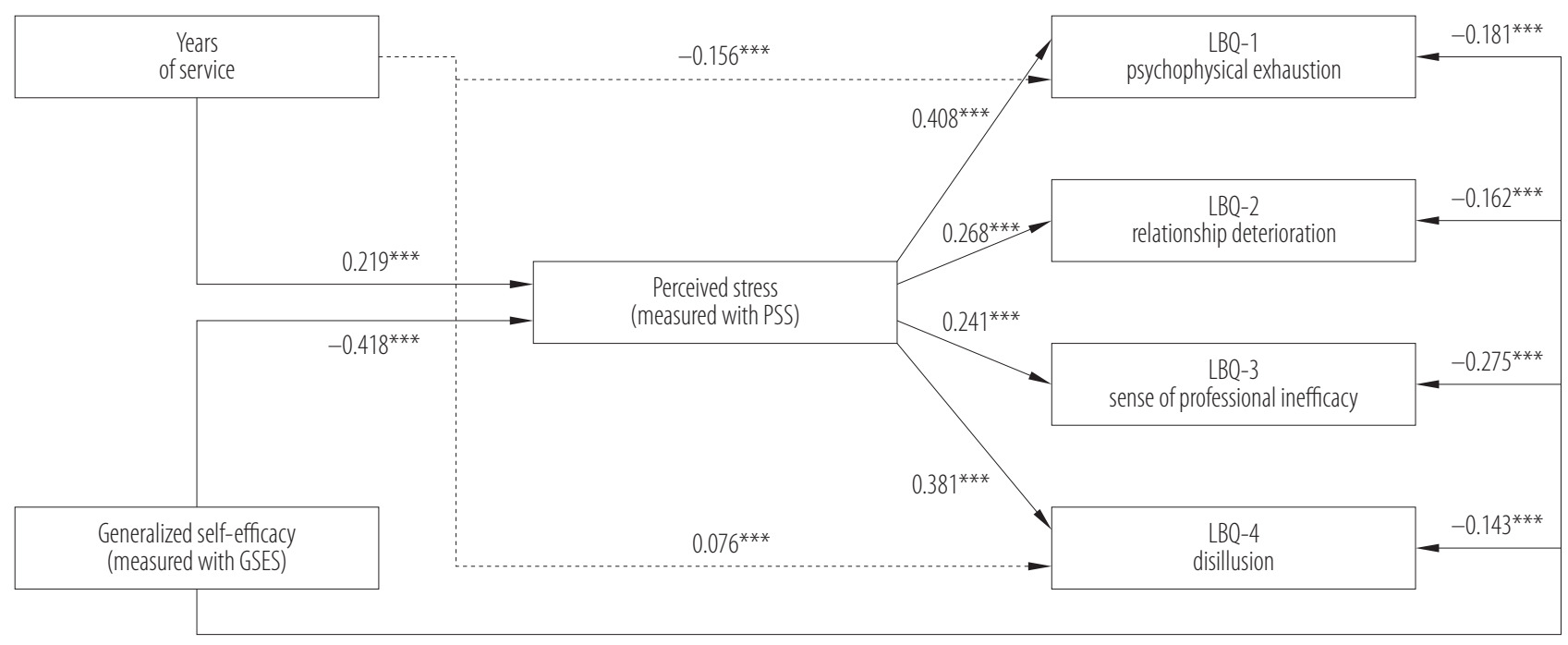

Matching indicators: $\mathrm{Chi}^{2}=0.145, \mathrm{df}=1, \mathrm{p}>0.05$, RMSEA $=0.001, \mathrm{CFI}=0.999$.

Explanations as in Figure 1.

For the readability of the graph, the graphic markings of irrelevant paths were omitted.

Figure 2. A model of path factors explaining various aspects of professional burnout in a group of firefighters.

ing to the number of years of service. The table also presents the results of the differences between the means of all participants, compared with the means of the subgroups which differed in terms of seniority. The results show that the variable "perceived stress" is higher in the group with a longer duration of service, and that this effect is similar for the following variables related to burnout: psychophysical exhaustion (LBQ-1) and disillusion (LBQ-4). The mean of the variable "lack of involvement in customer relations" was slightly lower in the group of participants working $>15$ years compared to those with fewer years of service.

The path model presented in Figure 2 contains 2 types of results:

- an estimation of the model fit, in which the indicators show that it has a good fit $\left(\chi^{2}=0.145, \mathrm{df}=1, \mathrm{p}>0.05\right.$, RMSEA $=0.001$, CFI = 0.999);

- standardized results of the estimation of the strength of the relationship between the variables included in the model.

The model did not include the variable "number of interventions," because its linear relationship with other variables was not shown at the earlier stage of the analysis (Table 1). As expected, the variable "generalized selfefficacy" affected both the level of perceived stress ( $\beta=$ -0.418) and all 4 aspects of professional burnout, of which the most significant variable was "the sense of professional inefficacy" (LBQ-3; $\beta=-0.275$ ).

Table 4 presents standardized results of estimating the impact of individual independent variables on the level of perceived stress and 4 aspects of occupational burnout. The total effect of a given independent variable on a dependent variable can easily be seen, as well as the distinction between direct and indirect effects. As can be seen from the table, the strongest relationship occurs between generalized self-efficacy and perceived stress $(\beta=-0.418)$.

\section{Additional analysis and results}

Tables 5 and 6 present a comparison of the average results obtained for married vs. unmarried firefighters, and those with children vs. those without children.

Tables 5 and 6 show that the subgroups of firefighters differ in the level of perceived stress and in only 1 aspect 
Table 4. Standardized results of regression analyses performed on the total effect, direct effect and indirect effect in group of active firefighters ( $\mathrm{N}=576)$ from 12 Polish voivodeships

\begin{tabular}{|c|c|c|c|c|c|c|c|c|c|}
\hline \multirow{3}{*}{ Variable } & \multicolumn{9}{|c|}{$\begin{array}{l}\text { Effect } \\
(\beta)\end{array}$} \\
\hline & \multicolumn{3}{|c|}{$\begin{array}{l}\text { generalized self-efficacy } \\
\text { (measured with GSES) }\end{array}$} & \multicolumn{3}{|c|}{ years of service } & \multicolumn{3}{|c|}{$\begin{array}{c}\text { perceived stress } \\
\text { (measured with PSS) }\end{array}$} \\
\hline & total & direct & indirect & total & direct & indirect & total & direct & indirect \\
\hline Perceived stress & -0.418 & -0.418 & 0.000 & 0.219 & 0.219 & 0.000 & 0.000 & 0.000 & 0.000 \\
\hline \multicolumn{10}{|l|}{ Burnout } \\
\hline psychophysical exhaustion (LBQ-1) & -0.351 & -0.181 & -0.171 & 0.132 & 0.042 & 0.089 & 0.408 & 0.408 & 0.000 \\
\hline relationship deterioration (LBQ-2) & -0.274 & -0.162 & -0.112 & -0.097 & -0.156 & 0.059 & 0.268 & 0.268 & 0.000 \\
\hline sense of professional inefficacy (LBQ-3) & -0.375 & -0.275 & -0.101 & 0.087 & 0.034 & 0.053 & 0.241 & 0.241 & 0.000 \\
\hline disillusion (LBQ-4) & -0.302 & -0.143 & -0.159 & 0.159 & 0.076 & 0.083 & 0.381 & 0.381 & 0.000 \\
\hline
\end{tabular}

GSES - Generalized Self-Efficacy Scale; LBQ - Link Burnout Questionnaire; PSS - Perceived Stress Scale.

Table 5. Comparison of the level of perceived stress and 4 aspects of burnout in married and unmarried firefighters, using Student's t-test, in a group of active firefighters from 12 Polish voivodeships

\begin{tabular}{|c|c|c|c|c|c|}
\hline \multirow[t]{2}{*}{ Variable } & \multicolumn{2}{|c|}{$\begin{array}{c}\text { Participants } \\
(\mathrm{N}=540) \\
(\mathrm{M} \pm \mathrm{SD})\end{array}$} & \multirow[t]{2}{*}{$\mathrm{t}$} & \multirow{2}{*}{$\mathrm{p}$} & \multirow[t]{2}{*}{ df } \\
\hline & $\begin{array}{l}\text { unmarried } \\
(\mathrm{N}=113)\end{array}$ & $\begin{array}{c}\text { married } \\
(\mathrm{N}=427)\end{array}$ & & & \\
\hline Perceived stress & $14.00 \pm 5.96$ & $15.19 \pm 5.82$ & 1.98 & 0.480 & 539 \\
\hline \multicolumn{6}{|l|}{ Burnout } \\
\hline psychophysical exhaustion (LBQ-1) & $15.22 \pm 5.33$ & $15.79 \pm 5.66$ & -0.97 & 0.330 & 539 \\
\hline relationship deterioration (LBQ-2) & $16.96 \pm 4.16$ & $16.44 \pm 4.38$ & 1.13 & 0.260 & 539 \\
\hline sense of professional inefficacy (LBQ-3) & $12.97 \pm 4.25$ & $13.58 \pm 4.45$ & -1.31 & 0.190 & 539 \\
\hline disillusion (LBQ-4) & $12.42 \pm 5.58$ & $13.96 \pm 6.16$ & -2.40 & $0.020^{*}$ & 539 \\
\hline
\end{tabular}

LBQ - Link Burnout Questionnaire.

* Statistical significance $<0.05$.

of occupational burnout, namely disillusion (LBQ-4). Although the differences have reached statistical significance, the absolute values are relatively modest.

\section{DISCUSSION}

The aim of this study was to analyze the impact of the following selected factors: the number of years of service, the number of interventions, generalized self-efficacy and perceived stress on 4 aspects of the professional burnout experienced by firefighters, namely psychophysical exhaustion, relationship deterioration, the sense of professional inefficacy, and disillusion. The most important results obtained in the research show that the number of interventions neither affected the level of perceived stress nor the individual aspects of occupational burnout. Although this result may seem surprising, it should be noted that 
Table 6. Comparison of the level of perceived stress and 4 aspects of burnout in firefighters with and without children, using Student's t-test, in a group of active firefighters from 12 Polish voivodeships

\begin{tabular}{|c|c|c|c|c|c|}
\hline \multirow[t]{2}{*}{ Variable } & \multicolumn{2}{|c|}{$\begin{array}{c}\text { Participants } \\
(\mathrm{N}=576) \\
(\mathrm{M} \pm \mathrm{SD})\end{array}$} & \multirow[t]{2}{*}{$\mathrm{t}$} & \multirow{2}{*}{$\mathrm{p}$} & \multirow[t]{2}{*}{ df } \\
\hline & $\begin{array}{l}\text { without children } \\
\quad(\mathrm{N}=169)\end{array}$ & $\begin{array}{l}\text { fathers } \\
(\mathrm{N}=407)\end{array}$ & & & \\
\hline Perceived stress & $13.81 \pm 5.94$ & $15.30 \pm 5.56$ & -2.88 & $0.010^{*}$ & 574 \\
\hline \multicolumn{6}{|l|}{ Burnout } \\
\hline psychophysical exhaustion (LBQ-1) & $15.39 \pm 5.32$ & $15.84 \pm 5.73$ & -0.87 & 0.380 & 574 \\
\hline relationship deterioration (LBQ-2) & $16.65 \pm 3.87$ & $16.51 \pm 4.60$ & 0.34 & 0.740 & 574 \\
\hline sense of professional inefficacy (LBQ-3) & $13.06 \pm 4.24$ & $13.63 \pm 4.45$ & -1.43 & 0.150 & 574 \\
\hline disillusion (LBQ-4) & $12.81 \pm 5.84$ & $14.07 \pm 6.22$ & -2.26 & $0.030^{*}$ & 574 \\
\hline
\end{tabular}

LBQ - Link Burnout Questionnaire.

* Statistical significance $<0.05$.

the variable "number of interventions" is quite general as it does not fully reflect the specificity of a firefighter's job. Firefighters, due to their profession, are exposed to situations that directly threaten their life and health, or involve being a witness to various human tragedies $[1,2,10,23,24]$. However, practicing this profession does not necessarily mean that each intervention entails a high degree of stress and exposure to traumatic events. Therefore, the number of interventions probably does not correlate directly with the levels of experienced stress or the indicators of burnout. There are also studies $[1,30]$ indicating that firefighters may have a lower level of occupational burnout than other professional groups. Their authors claim that this may be related to some specific aspects of firefighters' work, namely the facts that between interventions they have the opportunity to rest and recover psychologically, they deal with "technical" assistance more often, and they are exposed to a lesser extent to the constant interpersonal stress with which police officers, teachers or nurses have to deal. In addition, it should be noted that PSS-10 was used in the present study, which examines the intensity of perceived stress associated with more general life situations than traumatic stress resulting from exposure to extremely stressful events $[38,39]$.

The obtained results confirmed the impact of seniority on the level of perceived stress and burnout by firefighters. Similar conclusions can be drawn as regards the relationship between seniority and the level of stress experienced by the firefighters. Both the correlation analysis and the subsequent analysis of the path model showed that the level of stress experienced by the firefighters increased as a function of the number of years of service.

This can possibly be understood by taking into account 2 factors. First of all, the number of years of service is often related to promotion to a higher rank, which creates a new scope of duties involving a gradual shift from executive functions to command functions. This, in turn, increases the scope of responsibility, including responsibility for the health and life of one's subordinates. Second, the number of years of service is also related to age, and it is, therefore, usually associated with a change in one's social, family and economic status. Young people are mainly responsible for themselves, which implies fewer financial responsibilities in comparison with older individuals who 
are more likely to start a family. These relationships in the surveyed group of firefighters are presented in Table 1 , where it is clearly visible that the firefighters with the fewest years of service are less likely to be married and have children (67\% married and $91 \%$ without children) compared to the firefighters with the longest duration of service (84\% married and $94 \%$ with children). In such situations, the psychological conflict concerning work involvement vs. personal and family matters may occur with a significant frequency.

A study by Shreffler et al. [42], conducted on a group of firefighters who were fathers, revealed the relationship between work overload, parental stress and the satisfaction with raising children. A study by Smith et al. [11] showed that both stress levels and the conflict arising from attempts to balance work vs. personal and family matters affected the level of occupational burnout. This, in turn, resulted in a lower number of activities that enhanced the firefighters' safety.

On the basis of the above literature, it was decided to perform additional statistical analyses that could confirm or reject, at least partly, these assumptions (Tables 5 and 6). The results showed that the subgroups of firefighters who were married and had children experienced higher levels of stress and elevated levels of 1 aspect of burnout, namely disillusion (LBQ-4). On the one hand, this somewhat confirms the above assumptions. On the other hand, it should be noted that only 2 of the 5 variables studied were significantly higher, and these differences are not too large. More discrete factors or variables not examined in this study might possibly play a role in this regard. The collected data do not allow determination of more detailed issues related, e.g., to the financial situation of the firefighters' families, the quality of their marriages, or other additional family and financial factors.

Results similar to those presented here have also appeared in studies of other professional groups that are not so directly exposed to threats to their own lives or health. For example, in a study by Stanetić and Tešanović [13], the age and work experience of doctors was associated with a higher level of perceived stress and a greater risk of burnout. Different results were obtained by Wang et al. [7], where the older teachers in their study showed fewer symptoms of professional burnout (emotional exhaustion) compared to the younger ones. These authors argued that this was influenced by the greater experience of older teachers, who are generally better at dealing with different professional situations, while younger teachers experience a difficult period of adaptation to new work situations. However, 2 main differences should be taken into account: the profession of a teacher differs from the medical or firefighting profession, where in many situations the positive effects of work are noticeable immediately (e.g., healing, saving one's life), while in the teaching profession, the effects of education can be usually seen after many years. In addition, there may be some cultural differences in professional standards or working conditions in the teaching profession [43].

The number of years of service also had a positive impact on 2 aspects of professional burnout: relationship deterioration (LBQ-2) and disillusion (LBQ-4). Importantly, the author of the LBQ test, Santinello [36], assumes that people with relatively short working hours are particularly exposed to occupational burnout - due to the painful realization that, especially early on in their careers, their idealistic expectations prove very different from reality. Thus, the results obtained in these studies are in contradiction with the assumptions made by the author of LBQ.

As expected, self-efficacy in these studies had a negative effect on both the level of perceived stress and all 4 aspects of professional burnout. The identified direction of the impact of this variable confirms previous research [21,23]. The theories advanced by Lazarus and Folkman [44] propose that, at the second phase of the second stress and coping loop, there is a secondary appraisal concerning the individual's own chances of dealing with a stressful 
situation. Hence, the belief in self-efficacy may contribute to the positive outcome of such an estimation (an individual's ability to cope with a difficult situation), and thus to the reduction in the level of experienced stress.

Regarding occupational burnout, the greatest direct impact of self-efficacy was noted in the lowering of the sense of professional inefficacy (LBQ-3), followed by psychophysical exhaustion (LBQ-1), relationship deterioration (LBQ-2) and disillusion (LBQ-4). Thus, the relationship between generalized self-efficacy and a specific (professional) sense of inefficacy was revealed. However, this association is not as strong as it could be expected. This is also visible in the result of the correlation presented in Table 1 - although the direction of the relationship is consistent with the predicted negative correlation, it is not too strong. This may indicate that the sense of professional efficacy may be influenced, to a large extent, by factors other than generalized self-efficacy. The generalized sense of self-efficacy, as shown in many studies, has a motivational meaning and affects commitment and perseverance in actions that are undertaken $[18,19,20,45]$. This probably explains the impact on all dimensions of professional burnout, and in particular on the reduced level of psychophysical exhaustion. In addition, the greater the degree of generalized self-efficacy, the smaller the likelihood of rejection of the people whom firefighters help, and of hostility and cynicism towards them [35].

This study gives guidance on some remedial actions and further research. Further research on the detailed definition of the content and the cause of emerging stress, as well as that which accompanies direct interventions, is recommended. Various methodologies and analyses could be used in this field, to study diverse types of stress and job strain, along with qualitative methods for the detection of more discrete information. It would be possible to create work programs with individual employees as well as system solutions. For example, employees with longer seniority, who take greater responsibility for the work of others, may need to be supported in this respect, e.g., by dividing that responsibility between several employees and providing help to ensure a balance between work and family life. It is also important to strengthen self-efficacy in individual employees, which can prevent both the negative effects of stress and professional burnout. The literature also describes one of the techniques to strengthen self-efficacy in individual employees, which can prevent both the negative effects of stress and burnout [46]. To the best of the authors' knowledge, there has been no research on the use of such methods in a group of firefighters.

Research into burnout therapy provides some possible solutions. First of all, as in medicine, prevention is better than cure. It is, therefore, worth monitoring the level of burnout in firefighters and using preventive programs that include, e.g., different ways of coping with stress [47]. Second, it is likely that attempts to prevent a high level of occupational burnout will be most effective when targeted on both the following aspects: individual changes (e.g., a change of beliefs, an ability to relax, an ability to take care of oneself, a healthy lifestyle) and organizational changes (in working time, holidays, proper management, communication at work, etc.) [48]. Third, firefighters presenting the symptoms of occupational burnout syndrome should pay particular attention to safety issues, as occupational burnout may contribute to the weakening of safetyrelated behaviors [11].

\section{Limitations}

One of the limitations of the present study is the arbitrary division of employees into subgroups with a short duration of service ( $0-3$ years), a medium duration of service (4-8 years), a long duration of service (9-15 years), and a very long duration of service ( $>15$ years), which was introduced at the research planning stage. Also, the use of an ordinal scale limited the possibilities of statistical analysis, and it would be advisable to use a ratio scale in the future [49]. 
Another limitation outlined above is the use of PSS-10 which examines the level of perceived stress associated with more general life situations than the traumatic stress resulting from exposure to extremely shocking events $[38,39]$. Although many variables were included in the study, others, such as family and financial issues, were not taken into account. Including them in the path analysis could have provided a more complete picture of the factors influencing and moderating burnout in firefighters.

\section{CONCLUSIONS}

The findings described here show interesting, though non-homogeneous, results. The results indicate that the number of interventions does not affect the level of experienced stress or particular aspects of burnout. This is inconsistent with both the intuitive understanding of the problem and previous reports. It should be borne in mind that the scale used to measure stress was related to the stress arising from everyday life, and not the traumatic stress associated with exposure to acute, shocking events. In addition, the research presented in this paper has shown that the number of years of service has a positive effect on the level of experienced stress and on occupational burnout. This direct impact manifests itself most significantly in 2 aspects of burnout: relationship deterioration and disillusion. The sense of self-efficacy, as expected by the authors, had an impact both on reducing the sense of stress and on all aspects of burnout.

\section{REFERENCES}

1. Ogińska-Bulik N, Kaflik-Pieróg M. [Work stress, self-efficacy and work burnout syndrom among firefighters]. Acta Univ Lodz Folia Psychol. 2003;7:37-47.

2. Sattler DN, Boyd B, Kirsch J. Trauma-exposed firefighters: relationships among posttraumatic growth, posttraumatic stress, resource availability, coping and critical incident stress debriefing experience. Stress Health. 2014;30(5):356-65, https://doi.org/10.1002/smi.2608.
3. Portero de la Cruz S, Vaquero Abellán M. Professional burnout, stress and job satisfaction of nursing staff at a university hospital. Rev Lat Am Enfermagem. 2015;23(3):543-52, https://doi.org/10.1590/0104-1169.0284.2586.

4. Wang Y, Ramos A, Wu H, Liu L, Yang X, Wang J, et al. Relationship between occupational stress and burnout among Chinese teachers: a cross-sectional survey in Liaoning, China. Int Arch Occup Environ Health. 2016;88(5):589-97, https://doi.org/10.1007/s00420-014-0987-9.

5. Kumar S. Burnout and doctors: prevalence, prevention and intervention. Healthcare. 2016;4(37):1-9, https://doi.org/10. 3390/healthcare4030037.

6. Makara-Studzińska M, Załuski M, Tylec A, Panasiuk L. Do Polish doctors suffer from occupational burnout syndrome? An attempt to find an answer - Pilot study. Ann Agric Environ Med. 2019;26(1):191-7, https://doi.org/10.26444/aaem/105392.

7. Wang Z, Liu H, Yu H, Wu Y, Chang S, Wang L. Associations between occupational stress, burnout and well-being among manufacturing workers: Mediating roles of psychological capital and self-esteem. BMC Psychiatry. 2017;17(1):364, https://doi.org/10.1186/s12888-017-1533-6.

8. Schaufeli WB, Peeters MCW. Job stress and burnout among correctional officers: A literature review. Int J Stress Manag. 2000;7(1):19-48, https://doi.org/10.1023/A:1009514731657.

9. Mitani S, Fujita M, Nakata K, Shirakawa T. Impact of posttraumatic stress disorder and job-related stress on burnout: a study of fire service workers. J Emerg Med. 2006;31(1):711, https://doi.org/10.1016/j.jemermed.2005.08.008.

10. Katsavouni F, Bebetsos E, Malliou P, Beneka A. The relationship between burnout, PTSD symptoms and injuries in firefighters. Occup Med. 2016;66(1):32-7, https://doi.org/ 10.1093/occmed/kqv144.

11. Smith TD, Hughes K, DeJoy DM, Dyal M-A. Assessment of relationships between work stress, work-family conflict, burnout and firefighter safety behavior outcomes. Saf Sci. 2018;103:287-92, https://doi.org/10.1016/j.ssci.2017.12.005.

12. Warr P. Age and occupational well-being. Psychol Aging. 1992;7(1):37-45, https://doi.org/10.1037/0882-7974.7.1.37. 
13. Stanetić K, Tešanović G. Influence of age and length of service on the level of stress and burnout syndrome. Med Pregl. 2013;66(3-4):153-62.

14. Brewer EW, Shepard L. Employee Burnout: A Meta-Analysis of the Relationship Between Age or Years of Experience. Hum Resour Dev Rev. 2004;3(2):102-23, https://doi. org/10.1177/1534484304263335.

15. Clark A, Oswald A, Warr P. Is job satisfaction U-shaped in age? J Occup Organ Psychol. 1996;69(1):57-81, https://doi. org/10.1111/j.2044-8325.1996.tb00600.x.

16. Cherniss C. Role of professional self-efficacy in the etiology and amelioration of burnout. In: Schaufeli WB, Maslach C, Marek T, editors. Professional burnout: recent developments in theory and research. London: Routledge; 2017. p. 135-49.

17. Bandura A. Social learning theory. Englewood Cliffs, NJ: Prentice Hall; 1977.

18. Bandura A. Cultivate Self-Efficacy for Personal and Organizational Effectiveness. In: Locke EA, editor. Handbook of Principles of Organizational Behavior. Chichester: John Wiley \& Sons, Ltd; 2009. p. 179-200.

19. Sawhney G, Jennings KS, Britt TW, Sliter MT. Occupational Stress and Mental Health Symptoms: Examining the Moderating Effect of Work Recovery Strategies in Firefighters. J Occup Health Psychol. 2018;23(3):443-56, https://doi.org/ 10.1037/ocp0000091.

20. Prati G, Pietrantoni L, Cicognani E. Self-Efficacy Moderates the Relationship between Stress Appraisal and Quality of Life among Rescue Workers. Anxiety Stress Coping. 2010;23(4): 463-70, https://doi.org/10.1080/10615800903431699.

21. Dudek B, Koniarek J. Relationship between sense of coherence and post-traumatic stress disorder symptom among firefighters. Int J Occup Environ Health. 2000;13(4):229-305.

22. Kaflik-Pieróg M, Ogińska-Bulik N. Occupational stress and health among Polish Profesional Firefighters. Sztuka Lecz. 2003;9(2):31-8.

23. Ogińska-Bulik N. [Occupational stress in social services professions. Sources - Consequences - Prevention]. Warsaw: Difin; 2006.
24. Kehl D, Knuth D, Hulse L, Schmidt S. Posttraumatic Reactions among Firefighters after Critical Incidents: Cross-National Data. J Aggress Maltreatment Trauma. 2014;23(8): 842-53, https://doi.org/10.1080/10926771.2014.938143.

25. Koniarek J, Dudek B. [Post-traumatic stress disorder and firefighters' attitude towards their job]. Med Pr. 2001;52(3):177-83. Polish.

26. Ogińska-Bulik N, Langer I. [Type D personality and strategies of dealing with stress, and intensification of PTSD symptoms in the group of firefighters]. Med Pr. 2007;58(4): 307-16. Polish.

27. Mockałło Z. [Posttraumatic stress in firefighting - review of research]. Bezp Pr Nauk Prakt. 2009;6(453):2-5. Polish.

28. Ogińska-Bulik N. [Negative and positive effects of traumatic experiences in a group of emergency service workers - the role of personal and social resources]. Med Pr. 2013;64(4):46372, https://doi.org/10.13075/mp.5893.2013.0048. Polish.

29. Witt M, Stelcer B, Czarnecka-Iwańczuk M. [Stress coping styles in firemen exposed to severe stress]. Psychiatr. Pol. 2018;52(3):543-55, https://doi.org/10.12740/PP/73837. Polish.

30. Basinska B, Wiciak I. Fatigue and professional burnout in police officers and firefighters. Intern Security. 2012;2:265-74.

31. Krok, D. Can Meaning Buffer Work Pressure? An Exploratory Study on Styles of Meaning in Life and Burnout in Firefighters. Arch Psychiatry Psychother. 2016;1:31-42, https://doi.org/10.12740/APP/62154.

32. Ogińska-Bulik N, Kaflik-Pieróg M. [Occupational stress in emergency service]. Łódź: WSHE; 2006. Polish.

33. National Fire Protection Association [Internet]. Quincy MA: NFPA; 2018 [cited 2019 Jan 22]. Evarts B, Molis JL. U.S. Firefighter Injuries - 2017. Available from: https://www.nfpa. org/-/media/Files/News-and-Research/Fire-statistics-andreports/Emergency-responders/osffinjuries.pdf.

34. U.S. Fire Administration [Internet]. Emmitsburg, MD: USFA; 2016 [cited 2017 May 22]. Firefighter fatalities in the United States in 2015. Available from: https://www.usfa. fema.gov/downloads/pdf/publications/ff_fatalities_2015.pdf. 
35. Santinello M. Link Burnout Questionnaire, Manual. Firenze: Organizzazioni Speciali; 2007.

36. Santinello M. [Link Burnout Questionnaire]. Warsaw: Laboratory of Psychological Tests of the Polish Psychological Society; 2014. Polish.

37. Jaworowska A. [Massimo Santinello Link Burnout Questionnaire. Polish normalisation]. Warsaw: Laboratory of Psychological Tests of the Polish Psychological Society; 2014. Polish.

38. Cohen S, Kamarck T, Mermelstein R. A Global Measure of Perceived Stress. J Health Soc Behav. 1983;24(2):385-96, https://doi.org/10.2307/2136404.

39. Juczyński Z, Ogińska-Bulik N. [Percived Stress Scale - PSS-10]. In: Juczyński Z, Ogińska-Bulik N, editors. [Tools for Measuring Stress and Coping with Stress]. Warsaw: Laboratory of Psychological Tests of the Polish Psychological Society; 2009. p. 11-22. Polish.

40. Schwarzer R, Jerusalem M. Generalized Self-Efficacy scale. In: Weinman J, Wright S, Johnston M, editors. Measures in health psychology: A user's portfolio. Causal and control beliefs. Windsor: NFER-NELSON; 1995. p. 35-7.

41. Juczyński Z. [General self-efficacy scale GSES]. In: Juczyński Z, editor. [Tools for Measuring in Health Promotion and Health Psychology]. Warsaw: Laboratory of Psychological Tests of the Polish Psychological Society; 2012. p. 89-94. Polish.
42. Shreffler KM, Meadows MP, Davis KD. Firefighting and Fathering: Work-Family Conflict, Parenting Stress, and Satisfaction with Parenting and Child Behavior. Fathering. 2011;9(2):169-88, https://doi.org/10.3149/fth.0902.169.

43. Ho IT, Hau KT. Australian and Chinese teacher efficacy: Similarities and differences in personal instruction, discipline, guidance efficacy and beliefs in external determinants. Teach Teach Edu. 2004;20:313-23.

44. Lazarus RS, Folkman S. Stress, appraisal, and coping. New York: Springer; 1984.

45. Juczyński Z. [Self-Eficacy - Theory and Measurement]. Acta Univ Lodz Folia Psychol. 2000;4:11-24. Polish.

46. Bresó E, Schaufeli WB, Salanova M. Can a Self-EfficacyBased Intervention Decrease Burnout, Increase Engagement, and Enhance Performance? A Quasi-Experimental Study. High Educ. 2011;61:339-55.

47. Awa WL, Plaumann M, Walter U. Burnout prevention: A review of intervention programs. Patient Educ Couns. 2010;78(2):184-90, https://doi.org/10.1016/j.pec.2009.04.008. 48. Maricuţoiu LP, Sava FA, Butta O. The effectiveness of controlled interventions on employees' burnout: A meta-analysis. J Occup Organ Psychol. 2016;89(1):1-27, https://doi.org/ 10.1111/joop.12099.

49. Brzeziński J. [Methodology of psychology research]. Warsaw: Wydawnictwo Naukowe PWN; 2019. Polish.

This work is available in Open Access model and licensed under a Creative Commons Attribution-NonCommercial 3.0 Poland License - http://creativecommons.org/ licenses/by-nc/3.0/pl/deed.en. 